\title{
DIFFERENT APPROACHES TO DEFINE EATING OCCASIONS AND ITS ASSOCIATIONS WITH WEIGHT STATUS
}

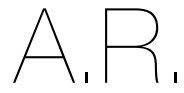
ARTIGO DE REVISÃO

1 EPIUnit - Instituto de Saúde Pública da Universidade do Porto, Rua das Taipas, n. ${ }^{\circ} 135$ 4050-600 Porto, Portugal

2 Departamento de Ciências da Saúde Pública e Forenses e Educação Médica da Faculdade de Medicina da Universidade do Porto,

Alameda Prof. Hernâni

Monteiro,

4200-319 Porto, Portugal

*Endereço para correspondência

Sofia Vilela

EPIUnit - Instituto de Saúde Pública da Universidade do

Porto,

Rua das Taipas, n. 135 ,

sofia.vilela@ispup.up.pt

Histórico do artigo:

Recebido a 4 de fevereiro de 201 Aceite a 10 de junho de 2019

\section{DIFERENTES ABORDAGENS PARA DEFINIR REFEIÇÕES E A SUA ASSOCIAÇÃO COM O PESO CORPORAL}

Sofia Vilela ${ }^{1,2} ;$ Carla Lopes ${ }^{1,2}$

\section{ABSTRACT}

A more holistic approach has been encouraged to explore complex issues, such as nutrition-related health outcomes, before addressing any specific question to explain the whole. The analysis at the meal pattern level allows assessing the combined effect of food compounds synergy and to be translated into meaningful results, such as dietary guidelines. This review describes different approaches to define eating occasions and previous evidence on the association between meal patterns and weight status. A variety of definitions of an eating occasion has been used in previous research, including 'time-of-day', 'participant-identification', 'food-based classification', and 'neutral'. Moreover, to optimize the differentiation between a main meal and a snack more than one criterion should be used. The inconsistency in definitions of eating occasions might impact the associations with health outcomes, namely body weight, and hamper data interpretation and comparison between studies.

\section{KEYWORDS}

Eating frequency, Holistic approach, Meal patterns, Obesity

RESUMO

Ao abordar problemas de saúde relacionados com alimentação, uma abordagem mais holística tem sido encorajada, antes de abordar qualquer questão específica para explicar o todo. A análise ao nível de padrões de refeição permite avaliar o efeito combinado da sinergia de diferentes alimentos e ser traduzida em resultados significativos, como recomendações alimentares. Esta revisão pretende descrever diferentes abordagens para definir refeições e evidência prévia sobre a associação entre o padrão da refeição e peso corporal. Uma variedade de definições do que constitui uma refeição tem sido usada em investigações anteriores, incluindo a 'hora do dia', 'identificação pelo participante', 'classificação baseada no alimento' e 'neutra'. Além disso, para otimizar a diferenciação entre uma refeição principal e um lanche (snack), mais de um critério deverá ser usado. A inconsistência nas definições do que constitui uma refeição, pode influenciar as suas associações com o peso corporal e dificultar a interpretação dos resultados e a comparação entre diferentes estudos.

PALAVRAS-CHAVE

Número de refeições, Perspetiva/abordagem holística, Padrão da refeição, Obesidade

\section{INTRODUCTION}

In the past decades, a reductionist approach has dominated nutrition research, with the focus on individual dietary constituents, such as essential nutrients, and their relationship with specific physiologic effects (1, 2). This reductionist paradigm consists of explaining a complex phenomenon by studying their separate entities' functional properties (3). This approach has led to a better understanding of how nutrients, or other bioactive compounds, affect human metabolism. For instance, the discovery of the role of vitamins had a huge impact on people's health, especially in developing countries where hypovitaminosis is prevalent (4). However, the increasing prevalence of diet-related chronic diseases, such as obesity and cardiovascular disease worldwide $(5,6)$ has pushed forward researchers to explore new ways to disentangle these phenomena, with real improvements in the public health. So recently, researchers have been encouraged to explore complex issues through a holistic view before addressing any specific question to explain the whole. In that way, strategies such as assessing dietary patterns rather than isolated food compounds or nutrients, or evaluating different dimensions of eating habits (e.g. diet quality and meal patterns) are encouraged. Moreover, the examination of food combination at the meal level provides an interesting approach, following this point of view, by expressing cumulative and interaction effects of foods and nutrients, overcoming the limitations of the study of nutrients or isolated foods. This review will explore different classification systems to define an eating occasion, and how this might influence the association between eating frequency and health outcomes, taking as an example the weight status. 


\section{Meal patterns: definition of an eating occasion}

A lack of public health recommendations on eating frequency or temporal distribution of meals is common at European level, especially in young populations (7). Eating behaviours can influence the diet quality and health outcomes, being the 'skipping breakfast' the most reported eating behaviour associated with a worse diet quality $(8,9)$ and with poor cardiometabolic health outcomes, including a higher body mass index (BMI) $(10,11)$. Nevertheless, evidence for other types of eating behaviours, such as eating frequency, has been less consistent (12). One explanation is the inconsistency in definitions of eating behaviour, which might hamper data interpretation and comparison between studies (12). Accordingly, differences in the characterization of eating behaviours, namely those related to meal patterns, may affect the direction and magnitude of the association between diet and health outcomes (13).

The terms 'eating occasion' (EO) or 'eating event' are usually used to describe any occasion where food or drink is consumed, and thus includes all meal types. However, there is no consensus on a universal definition of what constitutes an $\mathrm{EO}$ and how to differentiate main meals from snacks (14). This differentiation requires attention, as people tend to give a different perception to an EO, which in turn could influence significantly their dietary intake. Experimental studies showed that adults who define a particular EO as a main meal, based on some eating cues (i.e. use of dishes and utensils and being seated at a table), may reduce caloric intake later in that day (15). In an intervention study, undergraduate students reported feeling less satiated by a snack than a meal, even when the two EO were isocaloric (16). These peculiarities highlight that simply the label of an $\mathrm{EO}$, by the individual, as meal or snack may influence food choice, satiety, and daily energy intake (17). Hence, researchers have advised to avoid the word 'snack' when collecting information on individuals' eating patterns and to simply ask participants, for example, to record meals and food and drinks consumed between meals (17). A variety of approach has been described in the literature to define an EO, main meals and snacks, namely time-of-day, participant-identified, food-based classification (FBC) and neutral (13). Each classification system has its own strengths and limitations, and can potentially influence the outcome and interpretation of results. These definitions are discussed below and summarized in Table 1.

\section{Time-of-day}

This approaches defines meals based on the time-of-day in which food or drinks were consumed. The main meal may be defined as the largest EO (e.g. the highest percentage of energy) occurring between specific time intervals, while smaller EOs and any EOs occurring outside these intervals are considered as snacks. While this approach is easy to apply and understand, it does not capture meals eaten at unusual times, such as among shift workers and it requires a measure of time of eating. In addition, a bias towards traditional eating patterns might occur, as these time frames might be influenced by local or cultural factors, limiting comparison across different countries or cultural groups. Moreover, a definition of meals based on time might become more complex on weekend days or during holidays periods (13).

\section{Neutral}

The neutral approach defines an EO as any occasion when foods or drinks are consumed. The advantage of this definition is that it can be standardized and results are more comparable over time and across studies. Additional criteria have been used to define EO using the neutral definition, such as the time intervals between EO (e.g. 15min), a minimum of energy per EO (e.g. $210 \mathrm{~kJ} / 50 \mathrm{Kcal}$ ) and whether beverage-only EO are included or not. Noteworthy, these criteria have also been used in other definitions, namely the time-ofday and participated-identified, in order to define a separate meal and/ or snack (13). A mixed approach, using both neutral and time-of-day approaches, was previously used to define EO among 4 and 7 -yearold Portuguese children. Using data from 3-day food diaries, EO was defined as any occasion when food or drink was consumed with 30 min apart and provided a minimum of $210 \mathrm{~kJ}$ (50 kcal) of energy (neutral approach) (18). Afterwards, a time-of-day approach was used to define a 'main meal' and a 'snack' event. The main meal was defined as the EO providing more energy content between 6 am and 9.30 am (breakfast), between 11 am and 2.30 pm (lunch) and between 7 and $9.30 \mathrm{pm}$ (dinner). All other eating occasions were considered snacks events. One of the limitations of using a time-of-day approach is that it does not capture unusual time of feeding, such as among shift workers, however, as the authors had evaluated eating frequency of young children, a more typical pattern of feeding is likely to occur.

\section{Participant-identified}

This definition implicates that participants are asked to report their own EO, distinguishing between main meals and snacks, usually using a list of pre-specified meal labels (e.g. breakfast, lunch, dinner, or snacks). This approach avoids the use of a complex criterion to classify main meals and snacks; however, the definition cannot be standardized due to participant's subjectivity (13). This definition relies on an individual's perception of a meal or snack which might vary, depending on using the terms 'a snack', 'snacks foods' or 'snacking' (17). Moreover, the researcher must decide how to treat the EOs that are not clearly defined as a main meal or a snack by the participant and whether EOs occurring close in time should

\section{Table 1}

Summary of different approaches used to define eating occasions (EO)

\begin{tabular}{|c|c|c|c|}
\hline APPROACH & DEFINITION & ADVANTAGES & LIMITATIONS \\
\hline Time-of-day & Based on time intervals during which EO occur & $\begin{array}{l}\text { Easy to apply and understand. Focus on 'when' } \\
\text { foods are consumed }\end{array}$ & $\begin{array}{l}\text { Bias towards traditional eating patterns. Not } \\
\text { apply to individuals with varied meal times (e.g. } \\
\text { shift workers) }\end{array}$ \\
\hline Participant-identified & $\begin{array}{l}\text { Participant report their own EO, using a list of } \\
\text { pre-specified meal labels }\end{array}$ & $\begin{array}{l}\text { Avoids the use of a complex 'a priori' definition } \\
\text { of different EO (e.g. meals and snacks) }\end{array}$ & $\begin{array}{l}\text { Definition is not standardized (participants' } \\
\text { subjectivity). Might occur researcher bias }\end{array}$ \\
\hline $\begin{array}{l}\text { Food-based } \\
\text { classification }\end{array}$ & $\begin{array}{l}\text { Foods are categorized into food categories } \\
\text { based on their nutritional profile. The } \\
\text { combinations determine the type of EO }\end{array}$ & $\begin{array}{l}\text { Provides information on both qualitative and } \\
\text { quantitative aspects of the patterning of eating } \\
\text { events }\end{array}$ & $\begin{array}{l}\text { Complex categorization system. Differences in } \\
\text { classification criteria of meals and snacks may } \\
\text { limit comparison across studies }\end{array}$ \\
\hline Neutral & $\begin{array}{l}\text { A neutral term (e.g. 'eating event') is used to } \\
\text { collect meal pattern data }\end{array}$ & $\begin{array}{l}\text { Standardized and consistent. Findings may be } \\
\text { more comparable over time and across studies }\end{array}$ & $\begin{array}{l}\text { Loss of qualitative information about } \\
\text { individuals' perceptions of what constitutes } \\
\text { a meal/snack. Need to add additional criteria } \\
\text { (e.g. minimum-energy criterion) }\end{array}$ \\
\hline
\end{tabular}


be combined using additional time criteria. Using national data from Portuguese 3-9-year-old children, the 'participant-identified' approach was used to define an EO (19). The main caregiver had identified 12 predefined food consumption occasions (ranging from 'before breakfast' to 'during evening/at night'). All EO reported in the food diaries were considered as separated intake occasions if the time of eating was different from another EO and providing at least $210 \mathrm{~kJ}$ (50 kcal) of energy. However, the differentiation between 'main meal' and 'snacks' events was performed a posteriori by the researchers: the main meals were defined as breakfast, lunch or dinner (respondents could only select one of each) and all the other eating occasions were classified as snacks. With this methodological decision, the authors were able to overcome some limitations of the 'participant-identified' approach, such as participants' subjectivity of what constitutes a main meal and what constitutes a snack.

\section{Food-based classification (FBC)}

In this approach, foods are categorized into food categories based on their nutritional profile. The type of $\mathrm{EO}$, ranging from a complete meal (high nutrient density) to a low-quality snack (low nutrient density), is based on food category combinations. Another variation of the FBC is to distinguish main meals and snacks based on core and non-core foods. This classification was first used by Lennernãs \& Andersson (20) and was based on seven food categories that included food items of similar nutrient characteristics within each category. Taking into consideration the combination of food categories each EO was categorized as any four types of main meals (e.g. complete meal, less balanced meal or vegetarian meal) or four types of snacks (eg. High-quality snacks). An EO was considered as a "meal" if had included more food categories for high nutrient density (e.g. meat and meat products, fish, vegetables, legumes, fruit and dairy) than a snack. In a practical example, an EO including only chocolate would be considered "low-quality snack", but an EO including both an apple and chocolate would be considered "Mixed-quality snacks". This approach intended to encompass both qualitative and quantitative aspects of meal patterns, however, due to its complex categorization is use is limited. Additionally, differences in criteria to classify meals and snacks (e.g. nutrient profiles vs. energy density of foods) may limit comparison across studies and generalizability of this classification (13).

A previous research (21) has examined the influence of eight different definitions of EO on the characterization of eating patterns among adults and the extent to which they predict the proportion of variance in the total energy intake. It was the neutral definition, with a 15-min time interval plus a $210 \mathrm{~kJ}$ (50 Kcal) energy criterion, which best predicted the variance in total energy intake. One of the advantages of using this definition is that it can be standardized and comparable over time and across different studies (13). Overall, the study showed that different approaches to the definition of EOs affect how eating patterns are characterized (21). Nevertheless, even in the absence of a universal definition, a clear description of what is considered to constitute an EO should always be provided in manuscripts investigating the topic of EO (22).

\section{Meal patterns and obesity}

Research at the 'meal' level has shown that specific meal characteristics, such as the nutrient composition, eating frequency or regularity of meals, could influence adverse outcomes in health, such as obesity, insulin resistance, and metabolic syndrome, independently of other risk factors (23-29). Most of the studies have focused particularly on the topic of eating frequency (26-35). In that way, increased eating frequency might actually lead to a higher exposure to energy-dense foods, such as fast food and soft drinks, and large-portion-size foods, resulting in an increased hunger, excess energy intake, and ultimately unhealthy body weight gain (30-32). Nevertheless, some studies among adults showed that a greater meal frequency is associated with a healthier weight status $(33,34)$. Indeed, a recent systematic review of 31 observational studies among adults (30), found fourteen studies that reported an inverse association between eating frequency and body weight or body composition, and seven studies reporting a positive association. Although in men, a potential protective effect was consistently described, the authors concluded that there was not enough evidence for establishing a clear association between eating frequency and body weight in adults. A previously meta-analysis (35) found an overall inverse association between eating frequency and the likelihood of being overweight or obese in children and adolescents. However, when stratified by sex, the effect remained significant only in boys. The presence of publication bias and heterogeneity of studies might in part explain these differences, and further research was advised. More recently, in centrally obese children, eating frequency was associated with a higher BMl and no association was found between physical activity level and eating frequency (36). Among very young children, using a longitudinal approach, the daily eating frequency was not associated with the current or subsequent change in BMI (37). The authors justified, in part, these null associations due to a potential improvement of internal energy self-regulation by young children, in comparison with older children (37). Among healthy weight children aged 9-10 years, increased eating frequency was positively associated with higher levels of physical activity and improved composition of snacks and breakfast in terms of F\&V, fat, fiber and carbohydrates (36). It was previously described that eating frequency is somewhat stable during childhood as a moderate correlation between the number of EO at 4 and 7 years of age was found (18). Also, using a robust definition of $\mathrm{EO}$, a lower daily eating frequency was associated with increased odds of being overweight or obese in a national representative sample of Portuguese children (19).

Overall, the results between eating frequency and weight status should be interpreted with caution due to potential methodological limitations associated with the different studies. Besides the difficulty in interpretation of previous research related to the fact that there is no universal definition about what constitutes an EO, main meals or a snack, assessment of eating frequency has often been based on self-reported questionnaires (38-44), while just a few have assessed eating frequency using information on actual dietary habits (using e.g. food diaries or $24 \mathrm{~h}$ recall) $(18,36,37,45)$. Another issue is the potential for underreporting by obese or overweight individuals (46, 47) that might confound the association between eating frequency and adiposity.

\section{CONCLUSIONS}

To optimize the definition of a main meal or a snack more than one criterion should be used. This would allow avoiding ambiguities about what constitutes a main meal and what constitutes a snack. The collection of the time of consumption, as well as the identification of the eating occasion by the participant, seems to be a recommended strategy to study the impact of specific meal patterns on health outcomes. A more consistent approach to the definition of EO will facilitate appropriate interpretation of present and future research, improving the knowledge of the role of eating frequency on health. 


\section{REFERENCES}

1. Hoffmann I. Transcending reductionism in nutrition research. Am J Clin Nutr. 2003;783 Suppl:514S-6S.

2. Fardet A, Rock E. Perspective: Reductionist Nutrition Research Has Meaning Only within the Framework of Holistic and Ethical Thinking. Advances in nutrition. 2018;96:655-70.

3. Porta M, Sander G, Miguel H, Silva IdS, Last JM, editors. A Dictionary of Epidemiology. 6th ed. New York: Oxford University Press; 2014.

4. Fardet A, Rock E. Toward a new philosophy of preventive nutrition: from a reductionist to a holistic paradigm to improve nutritional recommendations. Advances in nutrition. 2014;54:430-46.

5. Global, regional, and national age-sex specific mortality for 264 causes of death 1980-2016: a systematic analysis for the Global Burden of Disease Study 2016. Lancet. 2017;39010100:1151-210.

6. Ng M, Fleming T, Robinson M, Thomson B, Graetz N, Margono C, et al. Global, regional, and national prevalence of overweight and obesity in children and adults during 1980-2013: a systematic analysis for the Global Burden of Disease Study 2013. Lancet. 2014;3849945:766-81.

7. Berg C, Forslund HB. The Influence of Portion Size and Timing of Meals on Weight Balance and Obesity. Curr Obes Rep. 2015;41:11-8.

8. Ramsay SA, Bloch TD. Skipping breakfast is associated with lower diet quality in young US children. 2018.

9. Barr SI, DiFrancesco L, Fulgoni VL, 3rd. Breakfast consumption is positively associated with nutrient adequacy in Canadian children and adolescents. $\mathrm{Br} \mathrm{J}$ Nutr. 2014;1128:1373-83.

10. Burazeri G, Hyska J, Mone I, Roshi E. Breakfast Skipping Is an Independent Predictor of Obesity but not Overweight Among Children in a Southeastern European Population. Int J Vitam Nutr Res. 2017:1-7.

11. Deshmukh-Taskar P, Nicklas TA, Radcliffe JD, O'Neil CE, Liu Y. The relationship of breakfast skipping and type of breakfast consumed with overweight/obesity, abdominal obesity, other cardiometabolic risk factors and the metabolic syndrome in young adults. The National Health and Nutrition Examination Survey (NHANES): 1999-2006. Public health nutrition. 2013;1611:2073-82.

12. Mesas AE, Munoz-Pareja M, Lopez-Garcia E, Rodriguez-Artalejo F. Selected eating behaviours and excess body weight: a systematic review. Obesity reviews : an official journal of the International Association for the Study of Obesity. 2012;132:106-35.

13. Leech RM, Worsley A, Timperio A, McNaughton SA. Understanding meal patterns: definitions, methodology and impact on nutrient intake and diet quality. Nutrition research reviews. 2015;281:1-21.

14. Leidy HJ, Armstrong CL, Tang M, Mattes RD, Campbell WW. The influence of higher protein intake and greater eating frequency on appetite control in overweight and obese men. Obesity. 2010;189:1725-32.

15. Wansink B, Payne CR, Shimizu M. "Is this a meal or snack?" Situational cues that drive perceptions. Appetite. 2010;541:214-6.

16. Capaldi ED, Owens JQ, Privitera GJ. Isocaloric meal and snack foods differentially affect eating behavior. Appetite. 2006;462:117-23.

17. Hess JM, Jonnalagadda SS. What Is a Snack, Why Do We Snack, and How Can We Choose Better Snacks? A Review of the Definitions of Snacking, Motivations to Snack, Contributions to Dietary Intake, and Recommendations for Improvement. 2016;73:466-75.

18. Vilela S, Severo M, Moreira T, Oliveira A, Hetherington MM, Lopes C. Association between eating frequency and eating behaviours related to appetite from 4 to 7 years of age: Findings from the population-based birth cohort generation XXI. Appetite. 2019;132:82-90.

19. Vilela S, Correia D, Severo M, Oliveira A, Torres D, Lopes C. Eating frequency and weight status in Portuguese children aged 3-9 years: results from the cross-sectional National Food, Nutrition and Physical Activity Survey 2015-2016 Public Health Nutr. 2019 Oct;22(15):2793-2802.

20. LennernÄS M, Andersson I. Food-based Classification of Eating Episodes (FBCE) Appetite. 1999;321:53-65.
21. Leech RM, Worsley A, Timperio A, McNaughton SA. Characterizing eating patterns: a comparison of eating occasion definitions. Am J Clin Nutr. 2015;1025:1229-37.

22. Gregori D, Maffeis C. Snacking and obesity: urgency of a definition to explore such a relationship. J Am Diet Assoc. 2007;1074:562; discussion -3.

23. Deshmukh-Taskar PR, Nicklas TA, O'Neil CE, Keast DR, Radcliffe JD, Cho S. The relationship of breakfast skipping and type of breakfast consumption with nutrient intake and weight status in children and adolescents: the National Health and Nutrition Examination Survey 1999-2006. Journal of the American Dietetic Association. 2010;1106:869-78.

24. Pot GK, Hardy R, Stephen AM. Irregular consumption of energy intake in meals is associated with a higher cardiometabolic risk in adults of a British birth cohort. International journal of obesity. 2014;3812:1518-24.

25. Almoosawi S, Prynne CJ, Hardy R, Stephen AM. Time-of-day and nutrient composition of eating occasions: prospective association with the metabolic syndrome in the 1946 British birth cohort. International journal of obesity. 2013;375:725-31.

26. Sierra-Johnson J, Unden AL, Linestrand M, Rosell M, Sjogren P, Kolak M, et al. Eating meals irregularly: a novel environmental risk factor for the metabolic syndrome. Obesity. 2008;166:1302-7.

27. Farshchi HR, Taylor MA, Macdonald IA. Beneficial metabolic effects of regular meal frequency on dietary thermogenesis, insulin sensitivity, and fasting lipid profiles in healthy obese women. Am J Clin Nutr. 2005;811:16-24.

28. Leidy HJ, Campbell WW. The effect of eating frequency on appetite control and food intake: brief synopsis of controlled feeding studies. The Journal of nutrition. 2011;1411:154-7.

29. Toschke AM, Thorsteinsdottir KH, von Kries R. Meal frequency, breakfast consumption and childhood obesity. International journal of pediatric obesity. 2009;44:242-8.

30. Canuto R, da Silva Garcez A, Kac G, de Lira PIC, Olinto MTA. Eating frequency and weight and body composition: a systematic review of observational studies. Public Health Nutr. 2017;2012:2079-95.

31. Alhussain MH, Macdonald IA, Taylor MA. Irregular meal-pattern effects on energy expenditure, metabolism, and appetite regulation: a randomized controlled trial in healthy normal-weight women. Am J Clin Nutr. 2016;1041:21-32.

32. Louis-Sylvestre J, Lluch A, Neant F, Blundell JE. Highlighting the positive impact of increasing feeding frequency on metabolism and weight management. Forum Nutr. 2003;56:126-8.

33. Holmback I, Ericson U, Gullberg B, Wirfalt E. A high eating frequency is associated with an overall healthy lifestyle in middle-aged men and women and reduced likelihood of general and central obesity in men. The British journal of nutrition. 2010;1047:1065-73. 34. Huseinovic E, Winkvist A, Bertz F, Berteus Forslund H, Brekke HK. Eating frequency, energy intake and body weight during a successful weight loss trial in overweight and obese postpartum women. European journal of clinical nutrition. 2014;681:71-6. 35. Kaisari P, Yannakoulia M, Panagiotakos DB. Eating frequency and overweight and obesity in children and adolescents: a meta-analysis. Pediatrics. 2013;1315:958-67. 36. Jennings A, Cassidy A, van Sluijs EM, Griffin SJ, Welch AA. Associations between eating frequency, adiposity, diet, and activity in 9-10 year old healthy-weight and centrally obese children. Obesity. 2012;207:1462-8.

37. Taylor RW, losua E, Heath AM, Gray AR, Taylor BJ, Lawrence JA, et al. Eating frequency in relation to $\mathrm{BMl}$ in very young children: a longitudinal analysis. Public Health Nutr. 2017;208:1372-9.

38. Cassimos D, Sidiropoulos H, Batzios S, Balodima V, Christoforidis A. Sociodemographic and dietary risk factors for excess weight in a greek pediatric population living in Kavala, Northern Greece. Nutr Clin Pract. 2011;262:186-91.

39. Ahadi Z, Kelishadi R, Qorbani M, Zahedi H, Motlagh ME, Ardalan G, et al. Association between meal frequency with anthropometric measures and blood pressure in Iranian children and adolescents. Minerva Pediatr. 2016; [Epub ahead of print].

40. Barba G, Troiano E, Russo P, Siani A. Total fat, fat distribution and blood pressure according to eating frequency in children living in southern Italy: the ARCA project. Int J Obes (Lond). 2006;307:1166-9.

41. Mota J, Fidalgo F, Silva R, Ribeiro JC, Santos R, Carvalho J, et al. Relationships 
between physical activity, obesity and meal frequency in adolescents. Ann Hum Biol. 2008;351:1-10

42. Lagiou A, Parava M. Correlates of childhood obesity in Athens, Greece. Public Health Nutr. 2008;119:940-5.

43. Kosti RI, Panagiotakos DB, Mihas CC, Alevizos A, Zampelas A, Mariolis A, et al. Dietary habits, physical activity and prevalence of overweight/obesity among adolescents in Greece: the Vyronas study. Med Sci Monit. 2007;1310:CR437-44.

44. Carvalho Francescantonio Menezes $1 \mathrm{H}$, Borges Neutzling M, Aguiar Carrazedo Taddei JA. Risk factors for overweight and obesity in adolescents of a Brazilian University: a case-control study. Nutr Hosp. 2009;241:17-24.

45. Murakami K, Livingstone MB. Associations of eating frequency with adiposity measures, blood lipid profiles and blood pressure in British children and adolescents. The British journal of nutrition. 2014;11112:2176-83.

46. Wehling $\mathrm{H}$, Lusher J. People with a body mass index 30 under-report their dietary intake: A systematic review. J Health Psychol. 2017:1359105317714318.

47. Murakami K, Livingstone MB. Prevalence and characteristics of misreporting of energy intake in US adults: NHANES 2003-2012. The British journal of nutrition. 2015;1148:1294-303. 